\title{
In situ distributions and characteristics of heavy metals in full-scale landfill layers
}

\author{
Pin-Jing $\mathrm{He}^{\mathrm{a}, *}$, Zheng Xiao ${ }^{\mathrm{a}}$, Li-Ming Shao ${ }^{\mathrm{a}}$, Ji-Yu Yu ${ }^{\mathrm{b}}$, Duu-Jong Lee ${ }^{\mathrm{c}}$ \\ ${ }^{a}$ State Key Laboratory of Pollution Control and Resources Reuse, Tongji University, Shanghai 200092, China \\ ${ }^{\mathrm{b}}$ Hangzhou Tianziling Municipal Solid Waste Treatment Center, Hangzhou 310022, China \\ ${ }^{\mathrm{c}}$ Chemical Engineering Department, National Taiwan University, Taipei 10617, Taiwan
}

Received 28 February 2005; received in revised form 5 September 2005; accepted 22 March 2006

Available online 28 April 2006

\begin{abstract}
The leachate from methanogenic landfill normally contains low concentrations of heavy metals. Little samples had ever been collected from the full-scale landfill piles owing to technical difficulty for well drilling. We drilled two wells in Hangzhou Tianziling landfill, $20 \mathrm{~m}$ and $32 \mathrm{~m}$ in depth each, and collected solid samples of waste age of 1-4 years from both wells. The total amounts, the sequentially extracted amounts, and the chemical binding forms of heavy metals of the samples collected at different depths were measured. With the correlation between leachate production amount and the yearly rainfall amount, the leached ratio of the heavy metals were estimated only $0.13 \%, 1.8 \%, 0.15 \%$, and $0.19 \%$ of $\mathrm{Cu}, \mathrm{Cd}, \mathrm{Pb}$, and $\mathrm{Zn}$, respectively. The heavy metals amounts in the main compositions of MSW, like glass, food waste, paper, coal cinders, were measured using fresh MSW samples. Afterward, the contents of heavy metals initially landfilled were estimated. A positive correlation was noted between the measured and the estimated initial contents of heavy metals, indicating that the low migration of heavy metals in landfill layers. However, among the metals investigated, Zn has shown better mobility inside landfill layers.

Acid volatile sulfide (AVS) and the simultaneously extracted metals (SEM) were measured for all collected samples with optimal reaction conditions identified to yield nearly perfect sulfide recovery as follows: $100 \mathrm{~g}$ wet samples, $80 \mathrm{~mL} \mathrm{~min}^{-1} \mathrm{~N}_{2}$ flow rate, reaction time of 150 min. The SEM/AVS ratios ranged 25-45, indicating that the AVS was insufficient to immobilize the SEM. Sequential extraction using six-fraction scheme revealed that the sum of exchangeable and the avid soluble fractions of heavy metals follow: $\mathrm{Zn}>\mathrm{Cd}>\mathrm{Cu}, \mathrm{Ni}, \mathrm{Pb}>\mathrm{Cr}$. The insoluble fraction of heavy metals in MSW was high, for instance, over $80 \%$ for $\mathrm{Cr}$ and $\mathrm{Pb}$ high insoluble fractions of heavy metals in the landfilled MSW and the sorption capability of the methanogenic landfill layers should be responsible to the low concentrations of heavy metals found in leachate. (C) 2006 Elsevier B.V. All rights reserved.
\end{abstract}

Keywords: Municipal solid waste; Landfill; Heavy metals; Mobilization; Chemical speciation

\section{Introduction}

The leachate from methanogenic landfill contains low concentrations of heavy metals [1-3]. The evaluation of metal release potential from landfill needs the information of the total deposited refuse amount, its composition, and the historical records of the leachate quality. With limited data, the worse-case simulation could be achieved by analyzing the leachate quality at present time [4].

Bozkurt et al. [5] claimed that the mature refuse contained a high sorption capacity of heavy metals. The sulfide precipi-

\footnotetext{
* Corresponding author. Tel.: +86216598 6104; fax: +86 2165986104 . E-mail address: solidwaste@mail.tongji.edu.cn (P.-J. He).
}

tation corresponded to the low heavy metal concentrations in methanogenic leachate [6,7]. For Cr, which could hardly form insoluble sulfide precipitates, Jensen and Christensen [8] proposed that the hydroxide precipitate should be able to bind it firmly in landfill. The ratio of the simultaneously extracted metals (SEM) and acid volatile sulfide (AVS), SEM/AVS, has been used to correlate the bioavailability of heavy metals in sediments [9-13]. At a low SEM/AVS, most heavy metals are claimed to bind in sulfide form and should not be available under anaerobic environment. Martensson et al. [15] noted that the AVS of landfill leachate is far from sufficient to bind most SEM in the landfill. Hydroxide precipitate could form instead at $\mathrm{pH}$ above neutral as normally noted for methanogenic leachate [16]. Gounaris et al. [17] and Jensen and Christensen [8] noted that a large fraction of heavy metals was associated with the colloidal 


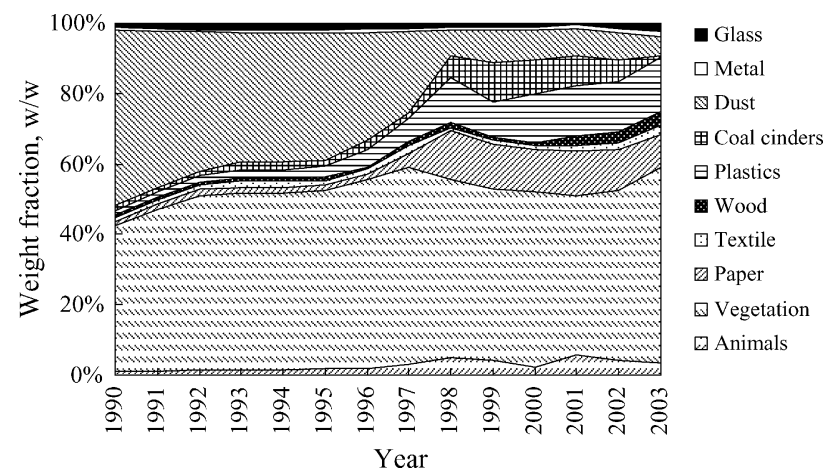

Fig. 1. Main ingredients of MSW of Hangzhou City over 1990-2003.

particles in landfill leachate. Klein and Nissner [18] found that the humic substance dominated colloidal particles in landfill leachate bound the main fraction of heavy metals in leachate. Kjeldsen et al. [19] comprehensively reviewed pertinent literature on leachate characteristics from MSW landfill.

To monitor the landfill leachate alone is hard to interpret why the mass amount of heavy metals could be immobilized in the landfill. However, to sample in situ is difficult in practice since the landfilled refuse contains texture to resist mechanical drilling. Also, the mechanical strength of the landfill body is generally not high enough to stabilize the well's wall. We drilled two wells in a full-scale landfill site, Tianziling landfill in Hangzhou, which is the first sanitary landfill site in PR China, and collected samples at different depths. The contents and the chemical binding forms of heavy metals of the samples collected at different depths were measured and profiled in this work.

\section{Materials and methods}

\subsection{The landfill}

The Tianziling landfill has received MSW from Hangzhou City since April 1991. Fig. 1 shows the main compositions of the collected MSW. The food waste presents a major composition which occupies more than 50\% (wet basis) since 1992 . Since the road dust was landfilled on the other site, its fraction reduced dramatically since year 1996. Coal was widely applied as household fuel over 1998-2002, which has been replaced by town-gas since 2003. The coal cinders presented up to $20 \%$ of the MSW around 2000, and had not appeared since 2003. The raw MSW apparently has a significant impact on the spatial changes of compositions in a landfill site.

The cross-section of the landfill site is profiled in Fig. 2, with bottom liners located at $54 \mathrm{~m}$ above sea level. The design capacity is $6,000,000 \mathrm{~m}^{3}$ and will be closed at the end of 2005 , and the top of the landfill will reach $165 \mathrm{~m}$ above sea level. The matured waste was located at bottom layers and the fresh one at top layers. For instance, the MSW of year 1999 was filled over the height of 102.5-110.0 m above sea level, and that of year 2002 over $127.5-135.0 \mathrm{~m}$. Two wells of depth $20 \mathrm{~m}$ and $32 \mathrm{~m}$ were drilled at the landfill site from the layer located $140 \mathrm{~m}$ above sea level, whose locations were also depicted in Fig. 1 for

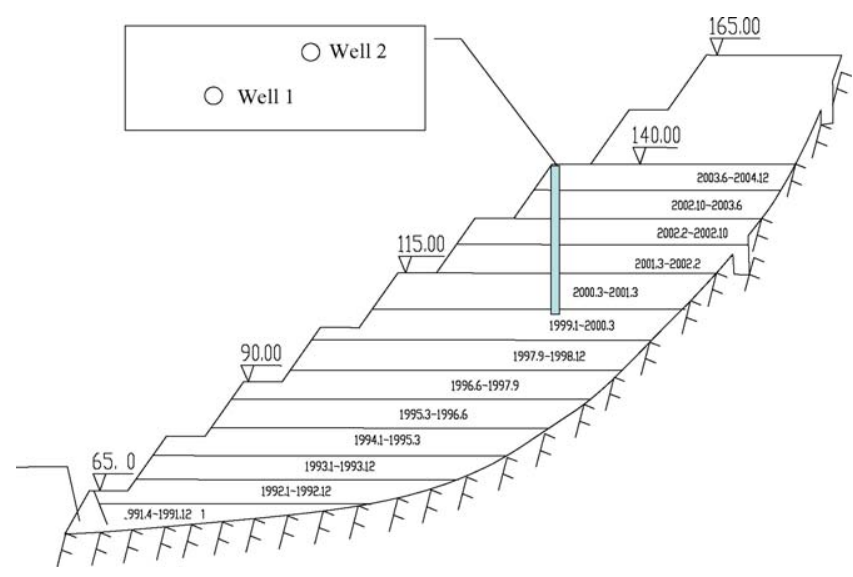

Fig. 2. The landfill site and the sampling wells.

demonstration purpose. The sampled MSW layer had a waste age of 1-4 years old.

\subsection{The samples}

The samples were collected at depths of $5 \mathrm{~m}, 10 \mathrm{~m}, 15 \mathrm{~m}$ and $20 \mathrm{~m}$ in well 1 , and of $5 \mathrm{~m}, 15 \mathrm{~m}, 25 \mathrm{~m}$ and $32 \mathrm{~m}$ in well 2, respectively. The physical characteristics of the MSW at different sites and depths are shown in Table 1. The bulk materials such as glass, plastic, textile, stone had been removed from the collected samples. The remaining part of the collected sample is the sample materials for further examination (the sample (a) in Table 1), occupying 46-84\% (wet basis) of the collected samples from the wells. The moisture contents of the wet samples were also listed in the last column of this table. Part of the samples were sealed in polyethylene black bag and kept at $4{ }^{\circ} \mathrm{C}$ in a refrigerator for AVS determination $[9,10]$. The rest of samples were air-dried and shredded into fine grain which was less than $2 \mathrm{~mm}$ size for other analysis items [11,12].

\subsection{Methods and apparatus}

\subsubsection{Element analysis}

The C, H, S contents in the collected samples (the sample (a) in Table 1) was analyzed using the LECO CHNS-932 elemental analyzer (LECO Corp., USA), and TKN measurement has been conducted for the $\mathrm{N}$ content in the collected samples.

\subsubsection{Total amounts of heavy metals}

The shredded samples were digested with a $\mathrm{HCl}-\mathrm{HNO}_{3}-$ $\mathrm{HF}-\mathrm{HClO}_{4}[20]$ mixture according to the procedure described below: (1) Adding 0.2000-0.5000 g sample accurately into a $50 \mathrm{~mL}$-crucible (PTFE). (2) The sample was first digested with $10 \mathrm{~mL}$ hydrochloric acid in an open crucible on a heat plate, whose temperature was about $200^{\circ} \mathrm{C}$. Digestion stopped when the hydrochloric acid was left less than $3 \mathrm{~mL}$. (3) Adding nitric acid $(5 \mathrm{~mL})$, hydrofluoric acid $(5 \mathrm{~mL})$ and perchloric acid $(3 \mathrm{~mL})$ in turn. After the crucible was lidded the sample was also heated for $1 \mathrm{~h}$. Then crucible was kept open and shaken occasionally to lose of silicon by its vaporization. The crucible was lidded 


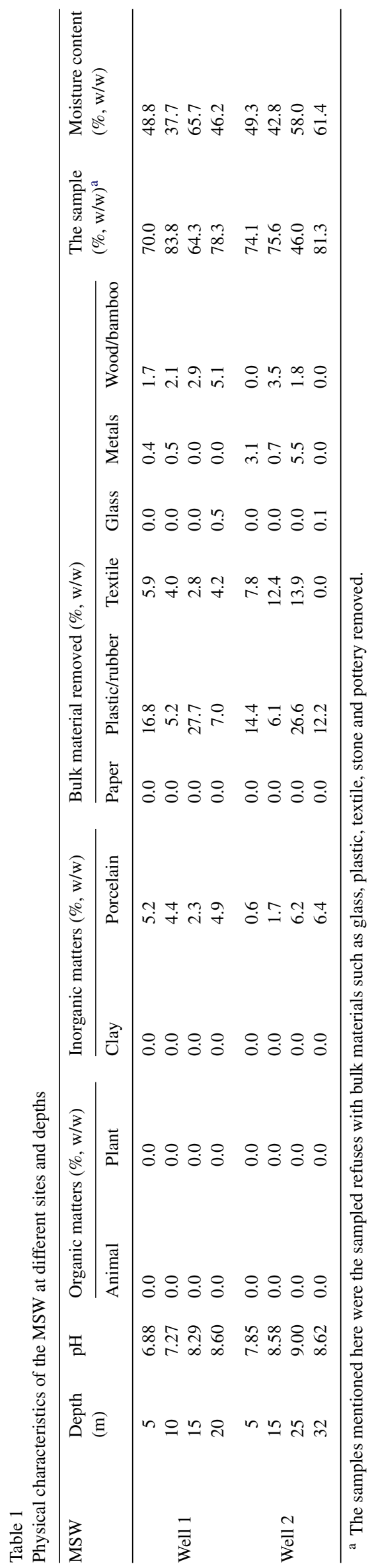

when white fumes appeared. After black organic carbon has disappeared the crucible was open to evaporate white fumes until the sample become dope. (4) The residue was dissolved in nitric acid $(1 \mathrm{~mL})$ and then diluted to $50 \mathrm{~mL}$. The solution was then analyzed by atomic absorption spectrometry (AAS), model 3200 (Shanghai Analytical Instrument Overall Factory, China) for $\mathrm{Cd}, \mathrm{Cu}, \mathrm{Pb}$ and $\mathrm{Zn}$, and model AA-6501F (Shimadzu Corporation, Japan) for $\mathrm{Cr}$ and $\mathrm{Ni}$.

\subsubsection{Sequential extraction procedures}

The sequential extraction procedures as follows were adopted to differentiate metals in the sampled waste into different fractions $[11,12]$ :

(1) Exchangeable fraction: $10 \mathrm{~mL}$ of $1 \mathrm{M} \mathrm{NH}_{4} \mathrm{Ac}(\mathrm{pH} 7)$ were added to $1.00 \mathrm{~g}$ shredded dry sample in a $50 \mathrm{~mL}$ plastic centrifuge tube. The mixture was continuously agitated (using a mechanical shaker) for $2 \mathrm{~h}$ and then centrifuged $(3000 \mathrm{rpm}$ for $30 \mathrm{~min}$ ). The supernatant solution was retained and used for analysis.

(2) Acid soluble fraction: $10 \mathrm{~mL}$ of distilled water were added to the residue from step (1) and centrifuged for $30 \mathrm{~min} .10 \mathrm{~mL}$ of NaAc and HAc mixture ( $\mathrm{pH} 5$ ) were added to the residue. The mixture was agitated for $5 \mathrm{~h}$ and centrifuged. The supernatant solution was used for analysis.

(3) Easily reducible fraction: $10 \mathrm{~mL}$ of distilled water were added to the residue from step (2) and centrifuged for 30 min. Twenty milliliters of $0.1 \mathrm{M} \mathrm{NH} \mathrm{N}_{2} \mathrm{OH} \cdot \mathrm{HCl}(\mathrm{pH} 2)$ were added to the residue from step (2). The mixture was agitated for $12 \mathrm{~h}$ and centrifuged. The supernatant solution was used for analysis.

(4) Moderately reducible fraction: $20 \mathrm{~mL}$ of $0.1 \mathrm{M}$ oxalate buffer ( $\mathrm{pH} 3$ ) were added to the residue from step (3). The mixture was agitated for $24 \mathrm{~h}$ and centrifuged. The supernatant solution was used for analysis.

(5) Oxidizable fraction: $20 \mathrm{~mL}$ of $30 \% \mathrm{H}_{2} \mathrm{O}_{2}(\mathrm{pH} 3)$ were added to the residue from step (4). The mixture was heated to $90^{\circ} \mathrm{C}$ until most of the hydrogen peroxide was evaporated. Following this treatment, $20 \mathrm{~mL}$ of $1 \mathrm{M} \mathrm{NH}_{4} \mathrm{Ac}(\mathrm{pH} 7)$ were added to the residue. The mixture was agitated for $12 \mathrm{~h}$ and centrifuged. The supernatant solution was used for analysis.

(6) Insoluble fraction: the residue from step (5) was dried at $105^{\circ} \mathrm{C}$ for $2 \mathrm{~h}$ and weighed. Then less than $0.5 \mathrm{~g}$ residue was digested following the same procedures in Section 2.3.2.

\subsubsection{AVS and SEM measurements}

Procedures for the determination of AVS and SEM in Allen and van Griethuysen $[13,14]$ were adopted here. The apparatus for measuring AVS and SEM of the landfill samples were shown in Fig. 3. Firstly nitrogen was deoxygenated by vanadous deoxygenating reagent in the first gas-washing bottle (3), then it was washed again by distilled water in the second gas-washing bottle (4). Hundred grams wet sample was placed in a $1000 \mathrm{~mL}$ flask (6) with stirring. Before test, the system was deoxygenated using nitrogen. Then $6 \mathrm{M} \mathrm{HCl}$ was added to the sample flask to keep $\mathrm{HCl}$ concentration in the mixture to be $1 \mathrm{M}[9,13]$. Bottles (7) and (8) were $\mathrm{H}_{2} \mathrm{~S}$ trap containing $0.5 \mathrm{M} \mathrm{NaOH}$. The trapped 


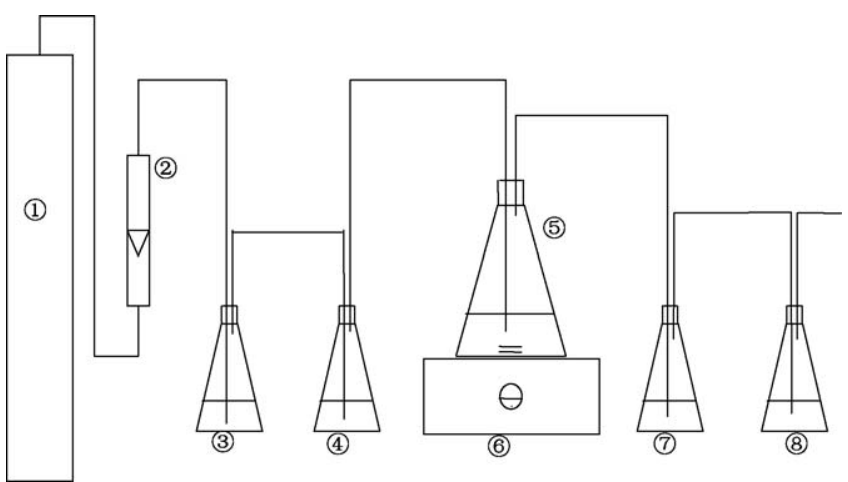

Fig. 3. Apparatus for measuring AVS and SEM in the landfill samples: (1) $\mathrm{N}_{2}$ cylinder; (2) flow controller; (3) $500 \mathrm{~mL}$ gas-washing bottles, containing oxygen scrubbing solution; (4) $500 \mathrm{~mL}$ gas-washing bottles, containing deionized water; (5) stirrer; (6) $1000 \mathrm{~mL}$ reaction flask (7) and (8) $200 \mathrm{~mL}$ trapping bottles, containing $80 \mathrm{~mL} 0.5 \mathrm{M} \mathrm{NaOH}$ solution.

$\mathrm{H}_{2} \mathrm{~S}$ was analyzed by colorimetric methods, and the solubilized metals (SEM) determined by AAS.

To approach the appropriate testing conditions for AVS/SEM, a standard solution containing $123.7 \mathrm{mg} \mathrm{L}^{-1}(10 \mathrm{~mL})$ sulfide was used as the testing material. For $\mathrm{N}_{2}$ flow rates ranging 60-100 $\mathrm{mL} \mathrm{min}^{-1}$, the AVS recovery exceeded $95 \%$, especially, reached $99 \%$ at a flow rate of $80 \mathrm{~mL} \mathrm{~min}^{-1}$ (Fig. 4a). We hence fixed the $\mathrm{N}_{2}$ flow rate used in further analysis at $80 \mathrm{~mL} \mathrm{~min}^{-1}$. Fig. $4 b$ shows the recovery of $\mathrm{H}_{2} \mathrm{~S}$ at different sample weight at a $\mathrm{N}_{2}$ flow rate of $80 \mathrm{~mL} \mathrm{~min}^{-1}$. Apparently when the sample weight is less than $110 \mathrm{~g}$ in the $1000 \mathrm{~mL}$ flask, the recovery reaction could be complete in less than $120 \mathrm{~min}$. Therefore, in the subsequent analysis, the reaction conditions were fixed as: $100 \mathrm{~g}$ wet samples, $80 \mathrm{~mL} \mathrm{~min}^{-1} \mathrm{~N}_{2}$ flow rate, reaction time of $150 \mathrm{~min}$.

\section{Results and discussion}

\subsection{Element analysis results}

The results for the shredded samples are shown in Table 2 . Most nitrogen has been leached out in the landfill, as shown by little nitrogen content in the collected samples, as a result of sufficient hydrolysis occurred in the landfilled MSW. The carbon content ranged $9.1-15.3 \%(\mathrm{w} / \mathrm{w})$. The sulfur content was about $0.2-0.5 \%(\mathrm{w} / \mathrm{w})$ in the collected samples.
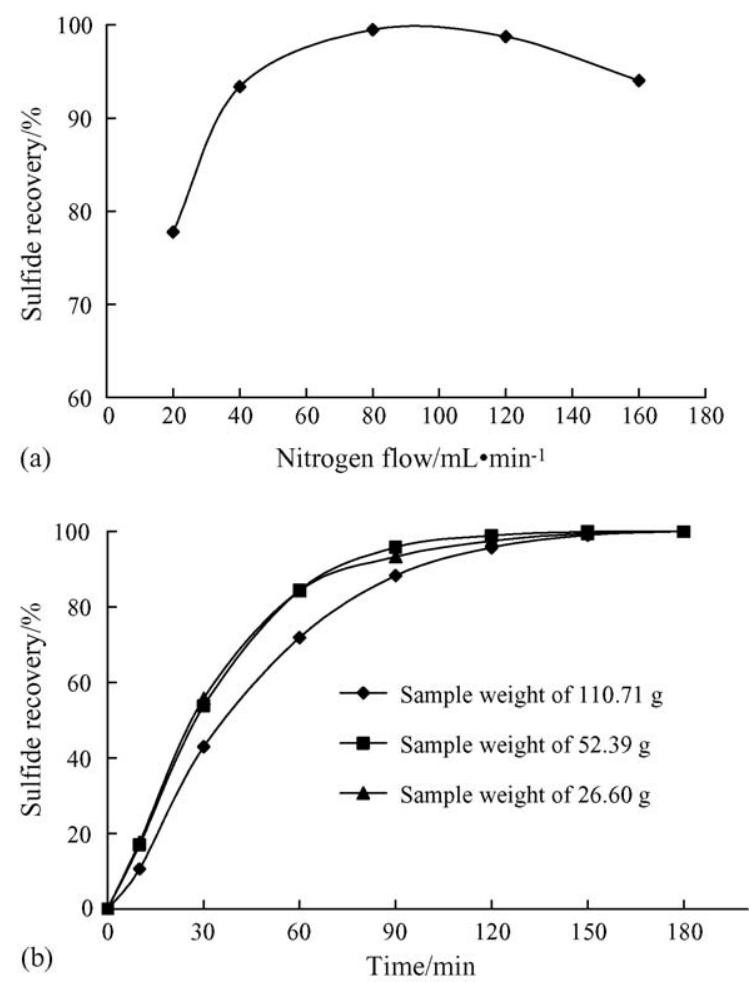

Fig. 4. (a) Effects of nitrogen flow rate on the recovery of $\mathrm{H}_{2} \mathrm{~S}$ from $\mathrm{Na}_{2} \mathrm{~S}$ suspension, $180 \mathrm{~min}$. (b) Effects of sample weight and reaction time on the recovery of $\mathrm{H}_{2} \mathrm{~S}$ from sample.

\subsection{The heavy metals in landfill}

Table 3 shows the heavy metal contents of collected samples. The contents follow the sequence: $\mathrm{Zn}>\mathrm{Pb}>\mathrm{Cr}>\mathrm{Cu}>\mathrm{Ni}>\mathrm{Cd}$. The heavy metal contents in landfill layers are much higher than those in surface soil samples as the backgrounds. Based on the average heavy metal contents of collected samples in the drilled well and the yearly landfill records, the total amount of $\mathrm{Cd}$, $\mathrm{Cu}, \mathrm{Pb}$, and $\mathrm{Zn}$ in the landfill could be estimated as 8.7 tonnes, 222 tonnes, 548 tonnes, and 808 tonnes, respectively (calculated from Table 4). Hence, the pollution potentials of the heavy metals from landfill leachate should be extremely high.

Based on the historical records of the precipitation and leachate production in the landfill over the past decade, the leachate production rate could be estimated by the yearly average rainfall rate with the follow equation: (leachate production rate $(10,000$ tonnes $)=0.0042 \times$ rainfall $\left(\mathrm{mm} \mathrm{a}^{-1}\right)$, with $\left.r^{2}=0.97\right)$.

Table 2

Elemental analysis for collected samples (the sample (a) in Table 1)

\begin{tabular}{|c|c|c|c|c|c|}
\hline MSW & Depth (m) & $\mathrm{C}(\%, \mathrm{w} / \mathrm{w})$ & $\mathrm{H}(\%, \mathrm{w} / \mathrm{w})$ & $\mathrm{TKN}(\%, \mathrm{w} / \mathrm{w})$ & $\mathrm{S}(\%, \mathrm{w} / \mathrm{w})$ \\
\hline \multirow{3}{*}{ Well 1} & 5 & 9.8 & 1.18 & 0.7 & 0.222 \\
\hline & 10 & 15.3 & 2.09 & 0.5 & 0.367 \\
\hline & 15 & 11.2 & 1.28 & 0.5 & 0.268 \\
\hline \multirow{2}{*}{ Well 2} & 5 & 14.8 & 1.68 & 0.6 & 0.252 \\
\hline & 10 & 9.3 & 1.03 & 0.3 & 0.543 \\
\hline
\end{tabular}



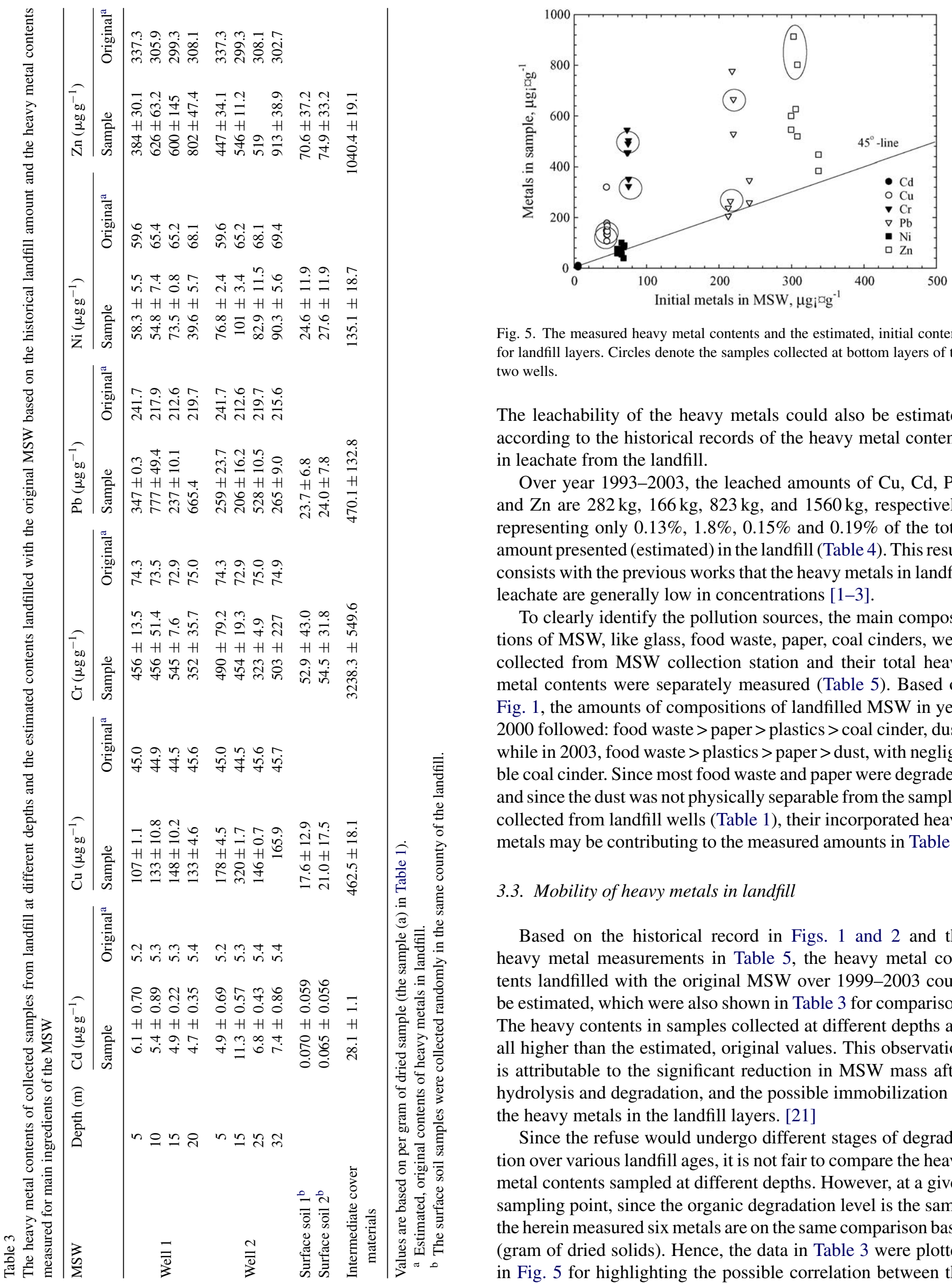

Fig. 5. The measured heavy metal contents and the estimated, initial contents for landfill layers. Circles denote the samples collected at bottom layers of the two wells.

The leachability of the heavy metals could also be estimated according to the historical records of the heavy metal contents in leachate from the landfill.

Over year 1993-2003, the leached amounts of $\mathrm{Cu}, \mathrm{Cd}, \mathrm{Pb}$, and $\mathrm{Zn}$ are $282 \mathrm{~kg}, 166 \mathrm{~kg}, 823 \mathrm{~kg}$, and $1560 \mathrm{~kg}$, respectively, representing only $0.13 \%, 1.8 \%, 0.15 \%$ and $0.19 \%$ of the total amount presented (estimated) in the landfill (Table 4). This result consists with the previous works that the heavy metals in landfill leachate are generally low in concentrations [1-3].

To clearly identify the pollution sources, the main compositions of MSW, like glass, food waste, paper, coal cinders, were collected from MSW collection station and their total heavy metal contents were separately measured (Table 5). Based on Fig. 1, the amounts of compositions of landfilled MSW in year 2000 followed: food waste $>$ paper $>$ plastics $>$ coal cinder, dust; while in 2003 , food waste $>$ plastics $>$ paper $>$ dust, with negligible coal cinder. Since most food waste and paper were degraded, and since the dust was not physically separable from the samples collected from landfill wells (Table 1), their incorporated heavy metals may be contributing to the measured amounts in Table 3 .

\subsection{Mobility of heavy metals in landfill}

Based on the historical record in Figs. 1 and 2 and the heavy metal measurements in Table 5, the heavy metal contents landfilled with the original MSW over 1999-2003 could be estimated, which were also shown in Table 3 for comparison. The heavy contents in samples collected at different depths are all higher than the estimated, original values. This observation is attributable to the significant reduction in MSW mass after hydrolysis and degradation, and the possible immobilization of the heavy metals in the landfill layers. [21]

Since the refuse would undergo different stages of degradation over various landfill ages, it is not fair to compare the heavy metal contents sampled at different depths. However, at a given sampling point, since the organic degradation level is the same, the herein measured six metals are on the same comparison basis (gram of dried solids). Hence, the data in Table 3 were plotted in Fig. 5 for highlighting the possible correlation between the 
Table 4

Precipitation, leachate production, heavy metals concentrations and migration rate of past 11 years from 1993 to 2003

\begin{tabular}{|c|c|c|c|c|c|c|c|c|c|c|c|c|c|}
\hline & & \multicolumn{11}{|l|}{ Year } & \multirow[t]{2}{*}{ Sum } \\
\hline & & 1993 & 1994 & 1995 & 1996 & 1997 & 1998 & 1999 & 2000 & 2001 & 2002 & 2003 & \\
\hline \multicolumn{2}{|l|}{$\begin{array}{l}\text { Landfilled MSW } \\
\text { [12] (104 tonnes) }\end{array}$} & 32 & 38 & 42 & 44.7 & 49 & 52.4 & 57.2 & 61.5 & 64.5 & 71.9 & 76.1 & 589.3 \\
\hline \multicolumn{2}{|l|}{$\begin{array}{l}\text { Precipitation } \\
\quad[12,13](\mathrm{mm})\end{array}$} & 1751 & 1399 & 1449 & 1482 & 1435 & 1538 & 1824 & 1198 & 1567 & 1744 & 854 & - \\
\hline \multicolumn{2}{|l|}{$\begin{array}{l}\text { Leachate production } \\
\quad\left(10^{4} \text { tonnes }\right)^{\mathrm{a}}\end{array}$} & 77.4 & 61.8 & 64.0 & 65.5 & 63.4 & 68.0 & 80.6 & 53.0 & 69.0 & 72.1 & 31.8 & 706.6 \\
\hline \multirow{3}{*}{$\begin{array}{l}\text { Concentrations } \\
\left(\mathrm{mg} \mathrm{L}^{-1}\right)^{\mathrm{b}}\end{array}$} & $\mathrm{Cd}$ & 0.012 & 0.014 & 0.021 & 0.022 & 0.022 & 0.055 & 0.034 & 0.012 & 0.017 & 0.022 & 0.022 & - \\
\hline & $\mathrm{Pb}$ & 0.166 & 0.044 & 0.056 & 0.112 & 0.112 & 0.105 & 0.210 & 0.103 & 0.109 & 0.112 & 0.112 & - \\
\hline & $\mathrm{Zn}$ & 0.119 & 0.115 & 0.121 & 0.245 & 0.245 & 0.331 & 0.261 & 0.260 & 0.249 & 0.245 & 0.245 & - \\
\hline \multirow{3}{*}{$\begin{array}{l}\text { Leached amount } \\
(\mathrm{kg})^{\mathrm{c}}\end{array}$} & $\mathrm{Cu}$ & 19.4 & 16.7 & 29.4 & 24.9 & 24.1 & 34.0 & 45.9 & 23.9 & 24.2 & 27.4 & 12.1 & 282 \\
\hline & $\mathrm{Cd}$ & 9.3 & 8.7 & 13.4 & 14.4 & 13.9 & 37.4 & 27.4 & 6.4 & 11.7 & 15.9 & 7.0 & 166 \\
\hline & $\mathrm{Pb}$ & 129 & 27.2 & 35.8 & 73.4 & 71.0 & 71.4 & 169.3 & 54.6 & 75.2 & 80.8 & 35.6 & 823 \\
\hline $\begin{array}{l}\text { Migration rates } \\
(\% \circ)^{d}\end{array}$ & $\mathrm{Zn}$ & 0.11 & 0.09 & 0.10 & 0.20 & 0.19 & 0.28 & 0.26 & 0.17 & 0.21 & 0.22 & 0.10 & 1.9 \\
\hline
\end{tabular}

measured heavy metal contents and the estimated, initial contents. If the heavy metals were easily migrated, all heavy metals should be washed out. In Fig. 5, however, a clearly positive correlation is noticeable for all cases. The data circled in Fig. 5 presented the samples collected at the bottom layers of wells. The heavy metals are thereby unlikely to move easily in the landfill. All data located above the $45^{\circ}$-line, mainly attributable to the degradation of organic matter to reduce the solids content.
However, the contents of $\mathrm{Cr}$ and $\mathrm{Cu}$ in the samples are much higher than in the original waste, which may be attributed to the intermediate cover materials, with extraordinary higher concentration of heavy metals, in the landfill (Table 3), although the mass amount of the intermediate cover materials was less than one tenth of the initially landfilled waste. The data of $\mathrm{Zn}$ and $\mathrm{Pb}$ deviated significantly from, while those of $\mathrm{Ni}$ located close to the $45^{\circ}$-line (Fig. 5). Since the samples collected at the same

Table 5

The heavy metal contents of different ingredients in MSW

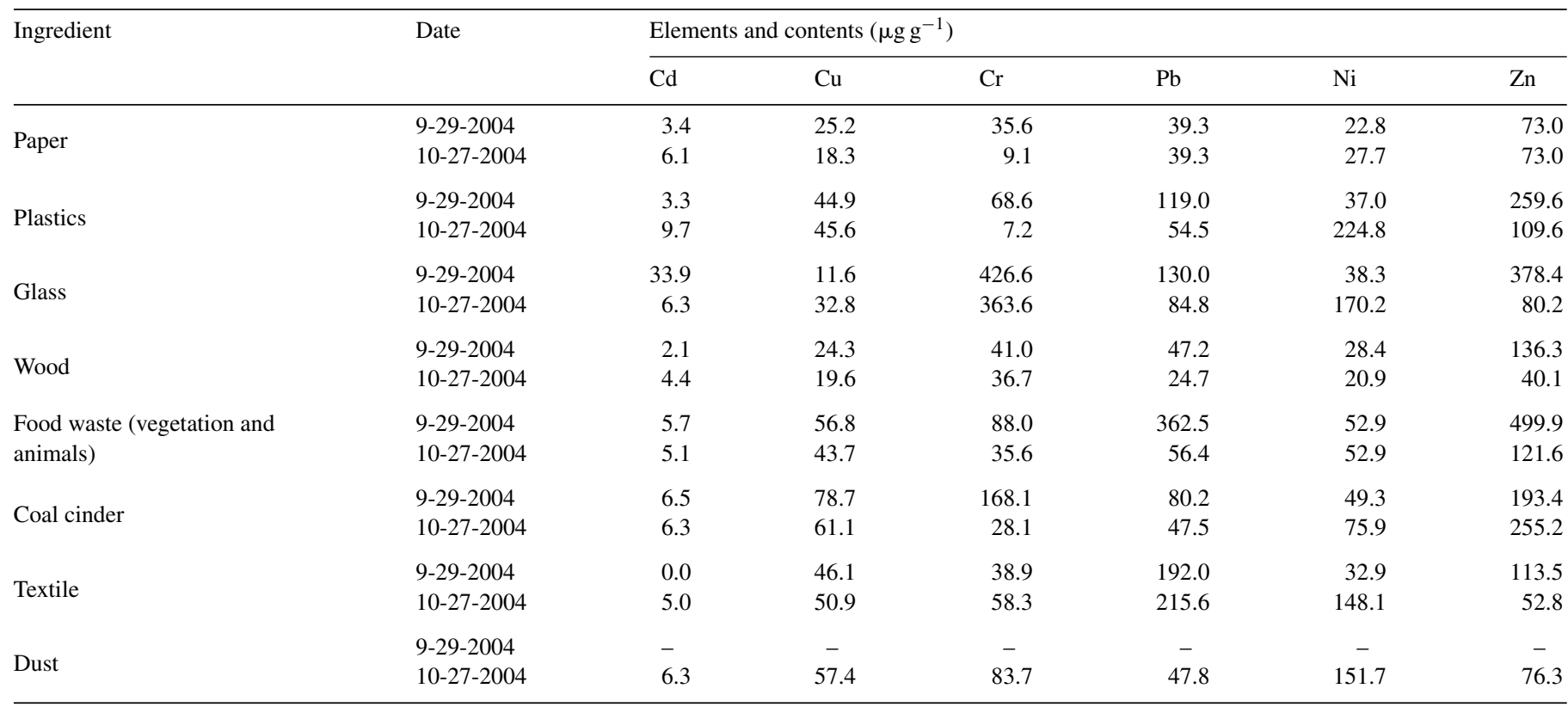



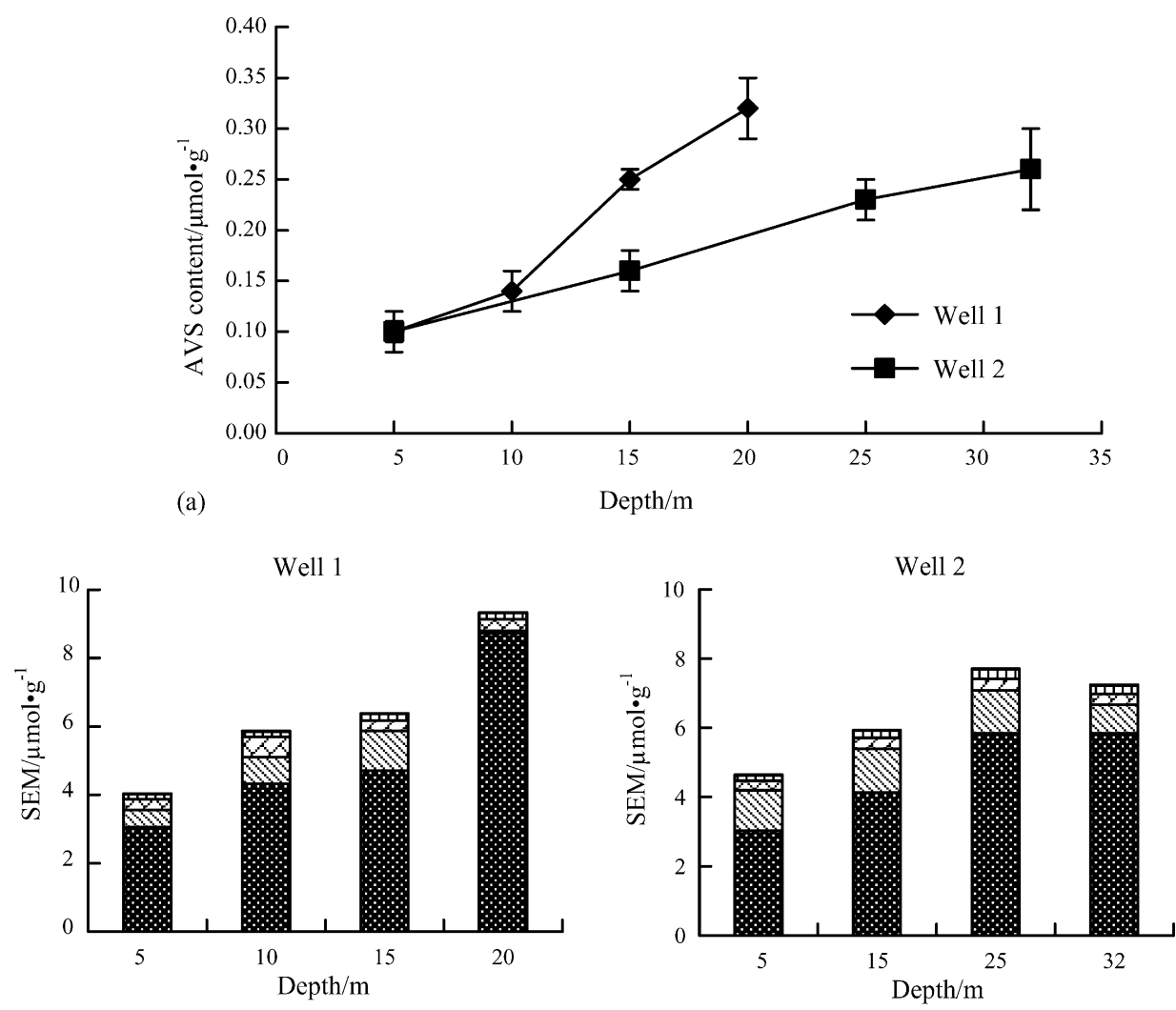

(b)

$\mathrm{Zn}$ 配 $\mathrm{BPb}$ 四i $\square \mathrm{Cd}$

$\mathrm{Zn} \quad \mathbb{\mathrm { Cl }} \quad \square \mathrm{Pb} \quad \mathbf{\mathrm { Ni }} \quad \square \mathrm{Cd}$

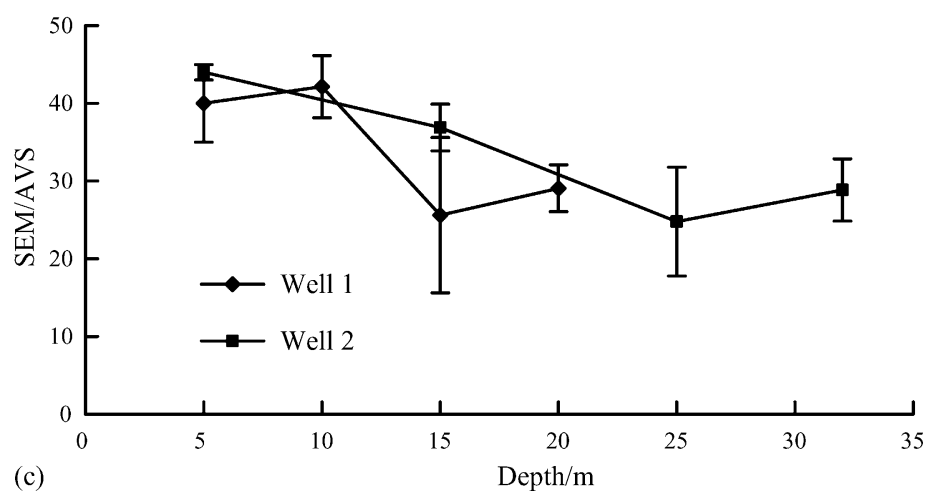

Fig. 6. (a) The AVS contents of the samples collected at different depths. (b) The SEM contents of the samples collected at different depths. (c) The SEM/AVS ratios of the samples collected at different depths.

depth should be having similar waste age, the noted difference (also shown in Table 3) revealed that the more percentage of $\mathrm{Ni}$ has been mobilized than $\mathrm{Zn}$ and $\mathrm{Pb}$ in landfill. However, since the leachate contains a low level of $\mathrm{Ni}$, the heavy metals released in the upper landfill layers may be immobilized again in the bottom layers. Additionally, the $\mathrm{Zn}$ concentrations at bottom layers (circled) were high than the initial concentrations, indicating the relatively high mobility of $\mathrm{Zn}$ in landfill.

\subsection{Measurements of AVS and SEM}

The AVS and SEM contents increase with increasing depths (Fig. 6a and b). The AVS ranged $0.10-0.32 \mu \mathrm{mol} \mathrm{g}^{-1}$ for well 1 , and $0.10-0.26 \mu \mathrm{molg}^{-1}$ for well 2 . Comparing with the sulfur contents listed in Table $2\left(2.2-5.4 \times 10^{-3} \mathrm{~g} \mathrm{~g}^{-1}\right.$ or $68.8-169 \mu \mathrm{mol} \mathrm{g}^{-1}$ ), only a small fraction of sulfur was present in sulfide form (or the forms soluble in $1 \mathrm{M} \mathrm{HCl}$ ). The AVS tends to move downward in the landfill. The mobility of sulfide is affected by the local liquid $\mathrm{pH}$, dropping from 6.8 to 7.8 at top layers to 8.6-9.0 at lower layers (Table 1). The sulfide is more readily fixed in environment at elevated $\mathrm{pH}$ values.

Hage and Mulder [22] have pointed out that the mobility of the heavy metals in the solid waste should be greatly dependent on $\mathrm{pH}$ in the liquid phase. Their results showed that at lower $\mathrm{pH}$ more components would be leached out than at neutral or alkaline conditions. As shown in Table 1, the $\mathrm{pH}$ of the collected samples raised from 6.8 to 7.8 at top layers to 8.6-9.0 at lower layers of landfill. The heavy metals in an easily mobilizing state 
$\mathrm{Cr}$

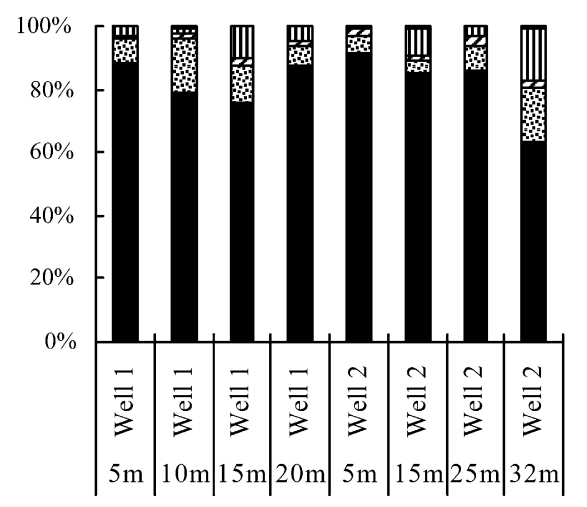

$\mathrm{Ni}$

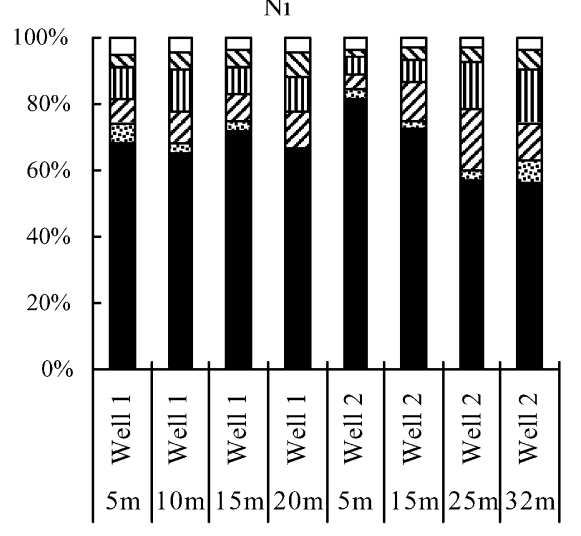

$\mathrm{Cu}$

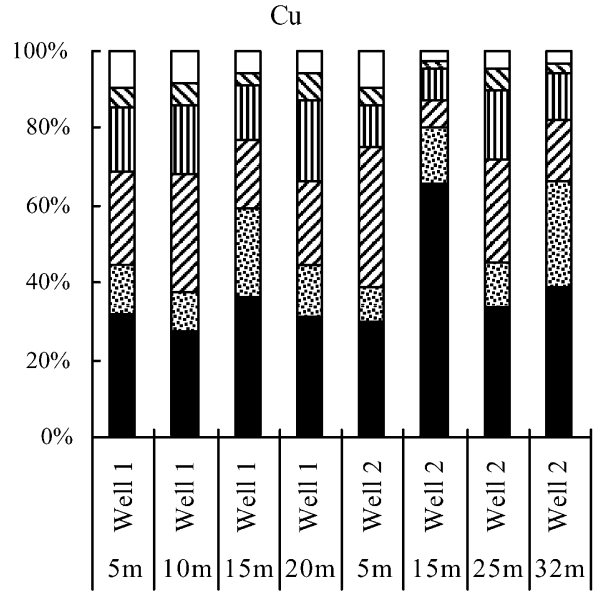

$\mathrm{Pb}$

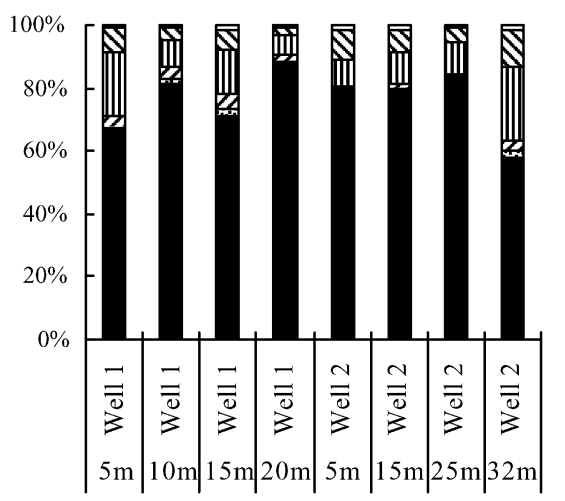

$\mathrm{Cd}$

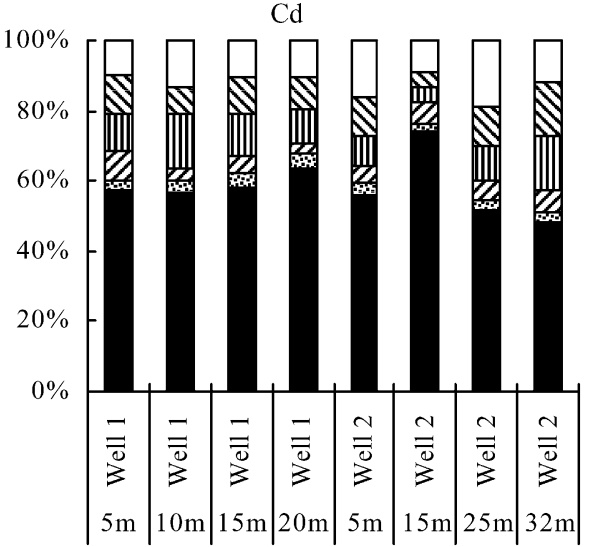

$\mathrm{Zn}$

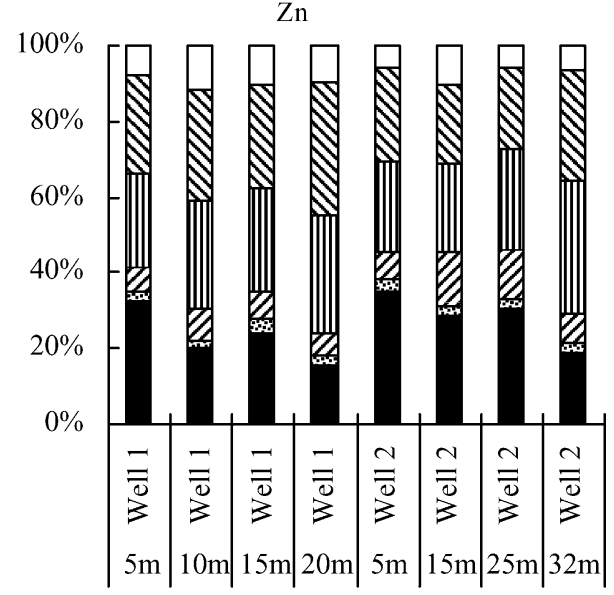

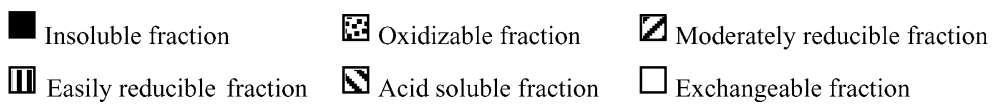

Fig. 7. Metal binding forms in the collected samples from well 1 and from well 2.

in the upper layers may move downward with leachate, and be fixed in the lower layers (Fig. 6b).

As Fig. 6b shows, the SEM mainly comprises of Zn (60-90\%) and $\mathrm{Cu}$ (up to $30 \%$ ). Comparing with the total heavy metals in the landfill (Table 3), the content of $\mathrm{Zn}$ in SEM ranged 3-8 $\mathrm{mol} \mathrm{g}^{-1}$, or $40-80 \%$ of the total $\mathrm{Zn}$. The mobility of $\mathrm{Zn}$ appears higher than those of the other four metals, corresponding to the observation noted in Table 3. Nonetheless, since the leachate contains a low level of $\mathrm{Zn}^{2+}$, the heavy metals released in the upper landfill layers must be immobilized again in the bottom layers.

The resulting SEM/AVS ratios are much greater than 1, ranging 25-45, and show a decreasing trend with increasing depth (Fig. 6c). The amount of AVS is insufficient to immobilize the SEM, correlating with the results by Martensson et al. [15] that sulfide is not a key binder to heavy metals in landfill. Field monitoring at Tianziling landfill revealed a high concentra- 
tion of sulfate in leachate, $90-190 \mathrm{mg} \mathrm{L}^{-1}$ in June, and up to $477 \mathrm{mg} \mathrm{L}^{-1}$ in August 2004. Most sulfur may simply wash out with leachate and insufficient AVS could be provided to bind heavy metals. Other binding forms may be available in landfill to immobilize the heavy metals.

\subsection{Metal binding forms}

Fig. 7 shows the binding forms of heavy metals of samples collected at different depths in landfill.

The exchangeable fractions of heavy metals follow: $\mathrm{Cd}>\mathrm{Zn}>\mathrm{Cu}>\mathrm{Ni}>\mathrm{Pb}>\mathrm{Cr}$. This fraction of heavy metals is easily removed by simple ion-exchange mechanisms, and correlated well with the leached amounts of heavy metals estimated in Table 5. The strong complexiation of $\mathrm{Cd}^{2+}$ and $\mathrm{Cl}^{-}$may result in high mobilization rate of $\mathrm{Cd}$ in landfill [19], because of high level of $\mathrm{Cl}^{-}$in landfill leachate.

The acid soluble fractions of heavy metals may be released in acidic environment, account for the possible release during refuse hydrolysis stage. This fraction decreases in the following order: $\mathrm{Zn}>\mathrm{Cd}>\mathrm{Pb}>\mathrm{Ni}>\mathrm{Cu}>\mathrm{Cr}$. The sum of the exchangeable fraction and the acid soluble fraction present the part of metals which have potential to release during refuse hydrolysis stage, whose magnitudes follow: $\mathrm{Zn}>\mathrm{Cd}>\mathrm{Cu}, \mathrm{Ni}, \mathrm{Pb}>\mathrm{Cr}$. It is obvious from Table 3 that $\mathrm{Zn}$ showed a higher mobility than did the other metals investigated, correlating to the noted, highest content of exchangeable and acid soluble fractions noted herein. However, the leachate contains low levels of $\mathrm{Zn}$, indicating that the leached $\mathrm{Zn}$ from the upper layers would be immobilized through certain mechanisms other than bound by sulfide at the bottom layers.

The insoluble fraction of heavy metals is not expected to be released in solution over a reasonable time span under the conditions normally encountered in nature [23]. Most heavy metals in landfill are noted in insoluble fraction. For $\mathrm{Cr}$ and $\mathrm{Pb}$, this fraction exceeded $80 \%$, and for $\mathrm{Zn}$ and $\mathrm{Cu}$, at least $20 \%$ (w/w). The heavy metals in landfilled MSW were mostly in residue fraction, which should be responsible to low concentrations of heavy metals in the leachate.

\section{Conclusions}

This work profiled how the heavy metals distributed in a full-scale landfill site, Hangzhou Tianziling landfill. Two wells were drilled in the landfill, $20 \mathrm{~m}$ and $32 \mathrm{~m}$ in depth each, from which solid samples of waste age of 1-4 years were collected. The total amount, the sequentially extracted amounts, and the solid metals binding forms of heavy metals of the samples collected at different depths were measured and profiled. The heavy metal contents of collected samples follow the sequence: $\mathrm{Zn}>\mathrm{Pb}>\mathrm{Cr}>\mathrm{Cu}>\mathrm{Ni}>\mathrm{Cd}$, while the amounts in the landfill were estimated as 8.7 tonnes, 222 tonnes, 548 tonnes, and 808 tonnes for $\mathrm{Cd}, \mathrm{Cu}, \mathrm{Pb}$, and $\mathrm{Zn}$, respectively. Based on the noted, linear relationship between leachate production rate and the yearly average rainfall rate, the leached ratio of $\mathrm{Cu}, \mathrm{Cd}, \mathrm{Pb}$, and $\mathrm{Zn}$ with leachate were estimated only $0.13 \%, 1.8 \%, 0.15 \%$ and $0.19 \%$ of the landfilled amounts over 1993-2003. The heavy metals in landfill were firmly bound and were difficult to release.

The main compositions of MSW, like glass, food waste, paper, coal cinders, were collected from MSW collection station and their heavy metal contents were separately measured. The compositions containing high concentrations of heavy metals include food waste $(\mathrm{Cu}, \mathrm{Cr}, \mathrm{Pb}, \mathrm{Zn})$, plastics $(\mathrm{Cd}, \mathrm{Cu}, \mathrm{Pb}, \mathrm{Ni}$, $\mathrm{Zn})$, coal cinders $(\mathrm{Cu}, \mathrm{Cr}, \mathrm{Zn})$, glass $(\mathrm{Cd}, \mathrm{Cr}, \mathrm{Ni}, \mathrm{Zn})$, dust $(\mathrm{Cu}$, $\mathrm{Cr}, \mathrm{Ni})$, and texture $(\mathrm{Cu}, \mathrm{Pb}, \mathrm{Ni})$. Based on the landfill ingredient amount and heavy metals contents thus measured, the initially landfilled heavy metals amount could be estimated. Owing to the hydrolysis and degradation of MSW, the measured heavy metal contents in samples collected at different depths were all higher than the estimated, initial values. A positive correlation was noted to exist between the measure and the estimated initial contents of heavy metals, indicating the low mobility of the metals in the landfill interior. Among the metals investigated, $\mathrm{Zn}$ has shown better mobility inside landfill layers.

Acid volatile sulfide and the simultaneously extracted metals were measured for all collected samples with optimal reaction conditions identified to yield nearly perfect sulfide recovery as follows: $100 \mathrm{~g}$ wet samples, $80 \mathrm{~mL} \mathrm{~min}^{-1} \mathrm{~N}_{2}$ flow rate, reaction time of $150 \mathrm{~min}$. The AVS and SEM contents increase with increasing depths, with the former ranged $0.10-0.32 \mu \mathrm{mol} \mathrm{g}-1$ for well 1 and $0.10-0.26 \mu \mathrm{mol} \mathrm{g}^{-1}$ for well 2 , and with the latter, 4.1-9.4 $\mu \mathrm{mol} \mathrm{g}^{-1}$ and 4.3-7.8 $\mu \mathrm{mol} \mathrm{g}^{-1}$, respectively. The SEM/AVS ratios ranged 25-45, indicating that the AVS was insufficient to immobilize the SEM. Most sulfur was leached out with leachate in the form of sulfate ions.

On the other hand, sequential extraction using six-fraction scheme revealed that the sum of exchangeable and the avid soluble fractions of heavy metals follow: $\mathrm{Zn}>\mathrm{Cd}>\mathrm{Cu}, \mathrm{Ni}, \mathrm{Pb}>\mathrm{Cr}$. This sum presented the fraction of heavy metals that had potential to be released in the refuse hydrolysis stage, corresponding to the noted highest mobility for $\mathrm{Zn}$ in the landfill. However, field data showed that the $\mathrm{Zn}$ concentration in leachate remained low, indicating that the leached $\mathrm{Zn}$ from the upper layers would be immobilized through certain mechanisms other than sulfide at the bottom layers. The insoluble fraction of heavy metals was high, for instance, over $80 \%$ for $\mathrm{Cr}$ and $\mathrm{Pb}$. The high insoluble fractions of heavy metals of landfilled MSW and the adsorption capability of the methanogenic landfill layers should be responsible to the low concentrations of heavy metals in leachate.

\section{Acknowledgement}

Support for this work by the Hi-Tech Research and Development Program (Nos. 2001AA644010, 2003AA644020) of China, is gratefully appreciated. Mention of trade names or commercial products does not constitute endorsement or recommendation for use.

\section{References}

[1] P. Flyhammar, Analysis of the cadmium flux in Sweden with special emphasis on landfill leachate, J. Environ. Qual. 24 (1995) 612-621. 
[2] H. Belevi, P. Baccini, Water and element fluxes from sanitary landfills, in: T.H. Christensen, R. Cossu, R. Stegmann (Eds.), Sanitary Landfilling: Process, Technology and Environment Impact, Academic Press Ltd., London, 1989.

[3] C. Aulin, I. Neretnieks, Material balance for an industrial landfill, in: T.H. Christensen, R. Cossu, R. Stegmann (Eds.), Proceedings of the Sardinia 95, Fifth International Landfill Symposium, vol. III, CISA Environmental Sanitary Engineering Centre, Cagliari, Italy, 1995, pp. 173180.

[4] J.K. Ǿygard, A. Mage, E. Gjengedal, Estimation of the mass-balance of selected metals in four sanitary landfills in Western Norway, with emphasis on the heavy metal content of the deposited waste and the leachate, Water Res. 38 (2004) 2851-2858.

[5] S. Bozkurt, L. Moreno, I. Neretsson, Long-term fate of organics in waste deposits and its effect on metal release, Sci. Total Environ. 228 (1999) $135-152$.

[6] T.H. Christensen, P. Kjeldsen, H.J. Albrechtsen, et al., Attenuation of landfill leachate pollutants in aquifers, Crit. Rev. Environ. Sci. Technol. 24 (1994) 119-202.

[7] A.S. Erses, T.T. Onay, In situ heavy metal attenuation in landfills under methanogenic conditions, J. Hazard. Mater. B99 (2003) 159-175.

[8] D.L. Jensen, T.H. Christensen, Colloidal and dissolved metals in leachates from four Danish landfills, Water Res. 33 (9) (1999) 2139-2147.

[9] Y.P. Hsieh, C.H. Yang, Diffusion methods for the determination of reduced inorganic sulfur species in sediments, Limnol. Oceanogr. 34 (1989) $1126-1130$

[10] C.E. Pesch, D.J. Hansen, W.S. Boothman, et al., The role of acid-volatile sulphide and intersitial water metal concentrations in determining bioavailability of cadmium and nickel from contaminated sediments to the marine polychaete neanthes arenaceodentata, Environ. Toxicol. Chem. 14 (1) (1995) 129-141.

[11] P. Flyhammar, Estimation of heavy metal transformations in municipal solid waste, Sci. Total Environ. 198 (1997) 123-133.
[12] P. Flyhammar, Use of sequential extraction on anaerobically degraded municipal solid waste, Sci. Total Environ. 212 (1998) 203-215.

[13] H.E. Allen, Analysis of acid-volatile sulphide (AVS) and simultaneously extracted metals (SEM) for the estimation of potential toxicity in aquatic sediments, Environ. Toxicol. Chem. 12 (1993) 1441-1453.

[14] C. van Griethuysen, Measuring acid volatile sulphide in floodplain lake sediments: effect of reaction time, sample size and aeration, Chemosphere 47 (2002) 395-400.

[15] A.M. Martensson, C. Aulin, O. Wahlberg, et al., Effect of humic substances on the mobility of toxic metals in a mature landfill, Waste Manage. Res. 17 (1999) 296-304.

[16] D.R. Reinhart, C.J. Grosh, Analysis of Florida MSW landfill leachate quality, Report 97-3, Florida Centre for Solid and Hazardous Management, Gainsville, FL, 1998.

[17] V. Gounaris, P.R. Anderson, T.M. Holsen, Characteristics and environmental significance of colloids in landfill leachate, Environ. Sci. Technol. 27 (1993) 1381-1387.

[18] T. Klein, R. Nissner, Characterization of heavy-metal-containing seepage water colloids by flow FFF, ultrafiltation, ELISA and AAS, Mikrochim. Acta 129 (1-2) (1998) 47-55.

[19] P. Kjeldsen, M.A. Barlaz, A.P. Rooker, A. Baun, A. Ledin, T.H. Christensen, et al., Present and long-term composition of MSW landfill leachate: a review, Crit. Rev. Environ. Sci. Technol. 32 (4) (2002) 297-336.

[20] State Environmental Protection Administration of China, soil qualitydetermination of total chromium, GB/T 17137-1997.

[21] P. Jain, H. Kim, T.G. Townsend, Heavy metal content in soil reclaimed from a municipal solid waste landfill, Waste Manage. 25 (2005) 25 35.

[22] J.L.T. Hage, E. Mulder, Preliminary assessment of three new European leaching tests, Waste Manage. 24 (2004) 165-172.

[23] A. Tessier, P.G.C. Campbell, M. Bisson, Sequential extraction procedure for the speciation of particulate trace metals, Anal. Chem. 51 (7) (1979) 844-850. 